\title{
Evolution of Lattice Spacing of Gamma Double Prime Precipitates During Aging of Polycrystalline Ni-Base Superalloys: An In Situ Investigation
}

\begin{abstract}
R.Y. ZHANG, H.L. QIN, Z.N. BI, J. LI, S. PAUL, T.L. LEE, S.Y. ZHANG, J. ZHANG, and H.B. DONG

Polycrystalline Ni-base superalloy Inconel 718 derives the strengthening mainly from $\mathrm{Ni}_{3} \mathrm{Nb} \gamma^{\prime \prime}$ phase. To investigate the evolution of lattice spacing of $\gamma^{\prime \prime}$ precipitates, in situ neutron diffraction experiments were performed during aging heat treatment of two Inconel 718 bar samples at $780{ }^{\circ} \mathrm{C}$ for 8 hours. One sample was aged with a negligible applied stress (5 MPa) and the other with an applied tensile stress of $300 \mathrm{MPa}$. The diffraction data demonstrate three stages of lattice spacing evolution due to compositional and morphological changes during aging. (1) Stage I, the $\gamma$ lattice spacing decreases isotropically in the first hour of aging as the composition changes. (2) Stage II, the $\gamma$ lattice spacing decreases and the $\gamma^{\prime \prime}$ lattice spacing increases between 1 and 5 hours of aging, at this stage compositional change on the lattice evolution weakens with aging time and the morphological change becomes comparable. (3) Stage III, as aging proceeds, compositional change is negligible, while morphological change is dominant; the $\gamma$ lattice spacing decreases in the longitudinal direction but increases in the transverse direction; in contrast, the converse occurs in $\gamma^{\prime \prime}$ lattice spacing evolution.
\end{abstract}

https://doi.org/10.1007/s11661-019-05536-y

(c) The Author(s) 2019

\section{INTRODUCTION}

INCONEL 718 (IN718) Ni-base superalloy, used widely in aero-engines and power plants for decades, derives its excellent high-temperature properties from the fine dispersion of $\mathrm{Ni}_{3} \mathrm{Nb}$ body-centered tetragonal (BCT) $\gamma^{\prime \prime}$ precipitates and the $\mathrm{Ni}_{3} \mathrm{Al} / \mathrm{Ti}$ simple cubic $\gamma^{\prime}$ precipitates. ${ }^{[1]}$ The $\gamma^{\prime \prime}$ phase has a volume fraction three times greater than the $\gamma^{\prime}$ phase and provides the major strengthening in this alloy. ${ }^{[2]}$ In addition, the $\gamma^{\prime \prime}$ phase has larger lattice parameters compared to the solid-solution FCC $\gamma$ matrix phase. ${ }^{[3]}$ Large lattice misfit arises between the $\gamma^{\prime \prime}$ and $\gamma$ phases accounting for the coherent strain strengthening in IN718. ${ }^{[4]}$ Extensive studies have shown that the volume fraction, size, morphology, and

R.Y. ZHANG, J. LI, S. PAUL, and H.B. DONG are with the Department of Engineering, University of Leicester, University Road, Leicester LE1 7RH, UK. Contact e-mail: hd38@le.ac.uk H.L. QIN, Z.N. BI, and J. ZHANG are with the High Temperature Materials Research Division, Central Iron and Steel Research Institute, No. 76 Xueyuannanlu, Haidian, Beijing, 100081, China. T.L. LEE is with the ISIS Neutron Source, Rutherford Appleton Laboratory, Harwell Science and Innovation Campus, Chilton, Oxfordshire, OX110QX, UK. S.Y. ZHANG is with the Centre of Excellence for Advanced Materials, No.1 Libin Road, Songshan Lake, Dongguan, 523808, China.

Manuscript submitted August 29, 2019.

Article published online November 11, 2019 distribution of the $\gamma^{\prime \prime}$ precipitates are key contributors to the mechanical performance of IN718. $\cdot^{[1,4-15]}$ A carefully designed heat treatment is necessary to achieve the desired microstructure for optimized properties. A typical heat treatment for IN718 consists of a solid-solution heat treatment to dissolve the equilibrium $\mathrm{Ni}_{3} \mathrm{Nb}$ $\delta$ phase followed by quenching, and a subsequent aging heat treatment for the precipitation of the $\gamma^{\prime \prime}$ phase. ${ }^{[16]}$

During the precipitation process, the size, distribution, and morphology of the $\gamma^{\prime \prime}$ precipitates are largely affected by the lattice misfit. Since the lattice misfit between the $\gamma^{\prime \prime}$ and the $\gamma$ phases is much greater along the $c$-axis ([001] direction) than that along the $a$-axis ([100] direction), the resultant misfit strain is anisotropic. This leads to a disc-like shaped growth of the $\gamma^{\prime \prime}$ precipitates with the $c$-axis normal to the disc-plane. ${ }^{[4]}$ When the $\gamma^{\prime \prime}$ precipitates are coherently embedded in the $\gamma$ matrix, the two phases maintain an orientation relationship of $\{100\} \gamma^{\prime \prime} / /\{100\} \gamma$ and [001] $\gamma^{\prime \prime} / /\langle 100\rangle \gamma$, and three possible variants of $\gamma^{\prime \prime}$ precipitates appear. ${ }^{[6]}$ When no external loads are applied or no residual stresses exist during aging (stress-free aging), the three variants distribute in approximately equal quantities. In the presence of an applied or residual stress (stress aging), different variants undergo different growth rates, resulting in, for example, only one dominant variant if its growth is substantially preferred. Such a stress-induced variant selection (SIVS) is attributed to the 
interaction between the applied or residual stresses and the misfit strain. ${ }^{[4,17,18]}$

Coarsening of the $\gamma^{\prime \prime}$ precipitates is of a great concern to IN718 since the size of precipitates has significant influences on the strengthening, and the continued growth of precipitates leads to loss of coherency and transformation from metastable $\gamma^{\prime \prime}$ phase to stable $\delta$ phase which is detrimental to the strengthening. Coarsening behavior of the $\gamma^{\prime \prime}$ precipitates has been studied by a few researchers, ${ }^{[3,12,13,18-20]}$ primarily confirming Lifshitz-Slyozov-Wagner (LSW) theory of particle coarsening and showing that this is controlled by the volume diffusion of $\mathrm{Nb}$ in the $\gamma$ matrix..$^{[3,13,20]}$ The coarsening kinetics of $\gamma^{\prime \prime}$ precipitates has been derived in a work by Devaux et al., ${ }^{12]}$ wherein the misfit strain of $\gamma^{\prime \prime}$ phase is taken as an important input parameter in determining the interfacial energy of $\gamma^{\prime \prime} / \gamma$. Extensive studies on the $\gamma^{\prime \prime}$ precipitation behavior have been reported in the literature from the view of the microstructure evolution. ${ }^{[5,6,12,13,20-25]}$ In contrast, studies on the evolution of lattice parameter or misfit associate with the $\gamma^{\prime \prime}$ precipitation is scarce in the literature. ${ }^{[3]}$

Lattice parameters of $\gamma^{\prime \prime}$ and $\gamma$ phases and the corresponding misfit strain are functions of (1) local elemental composition and (2) internal stress states, both of which would evolve with time during precipitation. For example, during the nucleation and early stage of growth of the $\gamma^{\prime \prime}$ precipitates, large $\mathrm{Nb}$ atoms migrate from the matrix to the $\gamma^{\prime \prime}$ phase, resulting in changes in the lattice parameters: an increase for $\gamma^{\prime \prime}$ phase and a decrease for the $\gamma$ matrix phase. ${ }^{[26]}$ During coarsening of the $\gamma^{\prime \prime}$ precipitates, lattice parameters will evolve to minimize the sum of interfacial and elastic strain energies. ${ }^{[27]}$ For the disc-shape $\gamma^{\prime \prime}$ precipitates, a large positive misfit strain occurs along the normal direction of the disc-plane resulting in an increase in the lattice parameter along this direction during coarsening and decrease along the in-plane direction. ${ }^{[28,29]}$ Consequently, the lattice parameter of the $\gamma$ matrix will tend to evolve in the contrary way compared to the $\gamma^{\prime \prime}$ phase to maintain the balance of elastic strain. Therefore, the correlation between the evolution of lattice parameters of both phases and the precipitation provides a complementary perspective to the microstructure characterization in studying the $\gamma^{\prime \prime}$ precipitation in IN718.

In the present study, in situ neutron diffraction measurements were performed to elucidate the evolution of lattice spacings of $\gamma^{\prime \prime}$ and $\gamma$ phases, and the corresponding misfit strains during aging heat treatment of IN718. By comparing the evolution of lattice spacings of two IN718 samples during stress-free and tensile-stress aging, respectively, the evolution of lattice spacings correlated to the $\gamma^{\prime \prime}$ precipitation process is revealed.

\section{EXPERIMENTAL PROCEDURES}

\section{A. Material}

Polycrystalline IN718 with nominal chemical composition listed in Table I was used in the current study. The IN718 material was manufactured through vacuum induction melting, electro-slag remelting, and vacuum arc remelting process. Rod specimens were extracted from forged IN718 which was solution heat treated at $1000{ }^{\circ} \mathrm{C}$ for 1 hour followed by fan cooling and then machining to tensile bar shape with gauge diameter of $8 \mathrm{~mm}$ and length of $42 \mathrm{~mm}$. The as-cooled microstructure consisted of grains with an average grain size of about $30 \mu \mathrm{m}$ with intermetallic $\delta$ phase at the grain boundaries.

\section{B. In situ Neutron Diffraction During Aging Heat Treatment}

The in situ neutron diffraction experiments were conducted in the ENGIN-X time-of-flight neutron diffractometer at the ISIS spallation neutron source, UK. ${ }^{[30]}$ The time-of-flight characteristic allows the simultaneous measurements of multiple diffraction peaks within a range of $\mathrm{d}$-spacing. The rod specimen was mounted onto a stress rig (INSTRON, 100KN) horizontally oriented at $45 \mathrm{deg}$ to the incident neutron beam. Bank 1 and bank 2 detectors located 90 deg to the incident beam at opposite directions, allowing the measurements of d-spacing along the longitudinal and transverse directions of the specimen, respectively. During the aging heat treatment, the specimens were heated in air by a radiative furnace equipped to the stress rig. A K-type thermocouple was mounted onto the surface of the rod specimens by means of twisting the thermocouple wires to control and monitor the temperature. A high-temperature ceramic extensometer was attached on the middle part of the specimen to monitor the strain developed during aging. A schematic illustration of the experiment setup is shown in Figure 1.

Two in situ neutron diffraction experiments were performed to study the $\gamma^{\prime \prime}$ precipitation behavior with tensile-stress-applied and stress-free, respectively. The two experiments were similar except that (i) a tensile stress of $300 \mathrm{MPa}$ was applied to the sample along the longitudinal direction for the tensile-stress aging, while a negligible tensile stress of $5 \mathrm{MPa}$ was applied for the stress-free aging, (ii) an acquisition time of about 7 minutes was employed for a satisfactory quality of $\gamma^{\prime \prime}$ peaks for the tensile-stress aging. In the case of stress-free aging, $\gamma^{\prime \prime}$ peaks were invisible, a shorter acquisition time was employed for a better time resolution. The diffraction parameters are summarized in Table II.

The purpose of the applied tensile stress in the first experiment was to introduce the SIVS effect on the $\gamma^{\prime \prime}$ variant distribution to facilitate the measurement of $\gamma^{\prime \prime}$ lattice spacing. ${ }^{[17]}$ In addition, the selected $\gamma^{\prime \prime}$ variant distribution will lead to anisotropic evolution of lattice spacing during aging, providing extra information for studying the relationship between the evolution of lattice spacing and precipitation process.

After the experiments, a tiny gap $(\sim<0.5 \mathrm{~mm})$ between the thermocouple contact pin and the sample surface was noticed. This indicated that the actual temperature of the sample during aging would have been higher than anticipated. In order to obtain information regarding the accurate sample temperature, 
Table I. Chemical Composition (Weight Percent)

\begin{tabular}{lccccccc}
\hline $\mathrm{C}$ & $\mathrm{Cr}$ & $\mathrm{Nb}$ & $\mathrm{Ti}$ & $\mathrm{Al}$ & $\mathrm{Mo}$ & $\mathrm{Ni}$ & $\mathrm{Fe}$ \\
\hline 0.02 & 19.03 & 5.06 & 1.00 & 0.54 & 3.06 & 52.16 & balance \\
\hline
\end{tabular}

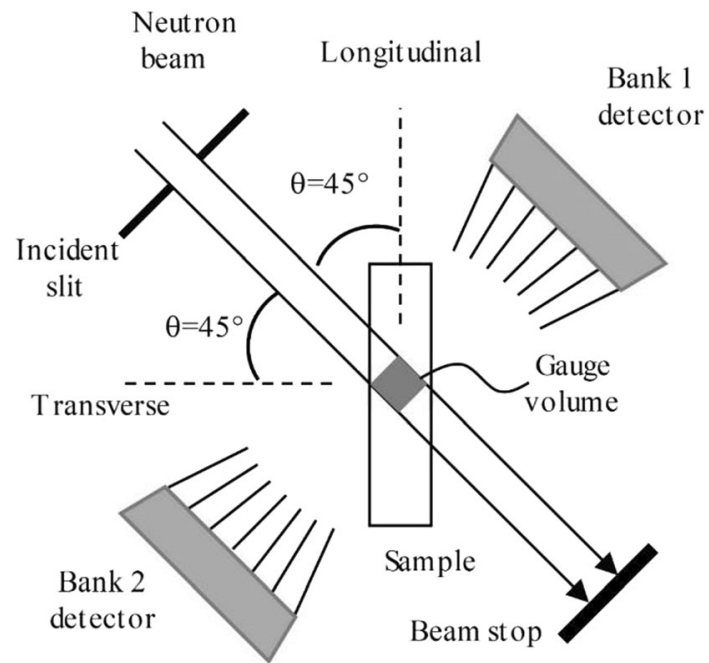

Fig. 1-Schematic layout of neutron diffraction experiment setup at ENGIN-X diffractometer, ISIS, UK.

Table II. In situ Neutron Diffraction Parameters Setup for Tensile-Stress Aging and Stress-Free Aging

\begin{tabular}{lll}
\hline Parameter & $\begin{array}{c}\text { Tensile-Stress } \\
\text { Aging }\end{array}$ & $\begin{array}{c}\text { Stress-Free } \\
\text { Aging }\end{array}$ \\
\hline Calibrated Temperature $\left({ }^{\circ} \mathrm{C}\right)$ & 780 & 780 \\
Heating Rate $\left({ }^{\circ} \mathrm{C} / \mathrm{min}\right)$ & 120 & 120 \\
Applied Tensile Stress $(\mathrm{MPa})$ & 300 & 5 \\
Stress Rate $(\mathrm{MPa} / \mathrm{s})$ & 5 & 5 \\
Acquisition Time $\left(\mathrm{min}^{3}\right)$ & 7 & 5.5 \\
Gauge Volume $\left(\mathrm{mm}^{3}\right)$ & $4 \times 4 \times 4$ & $4 \times 4 \times 4$ \\
\hline
\end{tabular}

a post-mortem temperature calibration was performed. The calibration was carried out using two thermocouples, one directly in contact with the specimen surface while the other was twisted around the sample in the same way as during the previous neutron diffraction experiment. The specimen was heated by the radiative furnace stepwise temperature increase. At each step, the set temperature was held for about 5 minutes to reach a homogeneous temperature distribution. The plot of the measured temperatures by the direct contact thermocouple against the thermocouple with a tiny gap is shown in Figure 2. A polynomial relationship (Eq. [1]) was obtained between the two sets of temperatures. This relationship was used to correct the temperature data from the previous experiments, and the actual aging temperature was revealed to be around $780{ }^{\circ} \mathrm{C}$. However, a temperature uncertainty of $\pm 10{ }^{\circ} \mathrm{C}$ might be expected since the precise gap dimension could vary

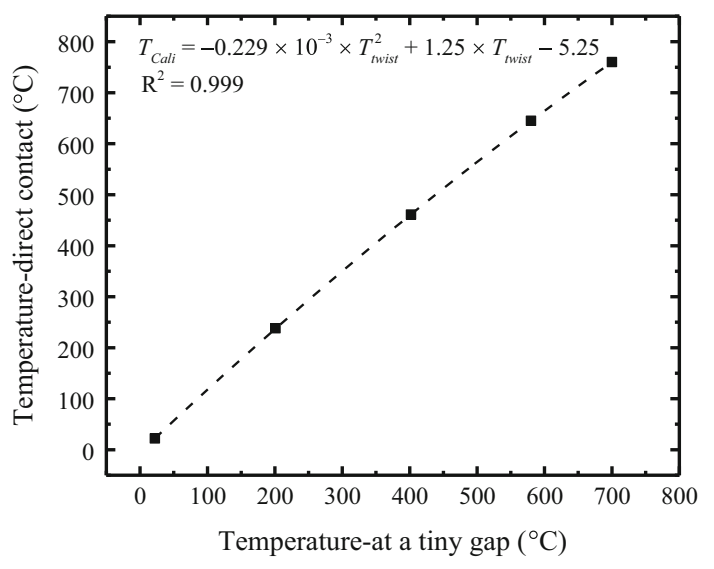

Fig. 2-Temperature calibration plot.

between different measurements. The equilibrium volume fraction of the $\gamma^{\prime}$ and $\gamma^{\prime \prime}$ may vary with temperatures, and JMatPro thermodynamic calculation predicts a drop in equilibrium volume fraction by 20 and 11 pct for the $\gamma^{\prime}$ and $\gamma^{\prime \prime}$, respectively, at $780{ }^{\circ} \mathrm{C}$ compared to $720{ }^{\circ} \mathrm{C}$. In addition, a higher aging temperature would lead to higher precipitation and coarsening rates. However, it is reasonable to believe that a higher aging temperature would have negligible influences on the objectives of the current study.

$$
T_{\text {Cali }}=-0.229 \times 10^{-3} \times T_{\text {twist }}^{2}+1.25 \times T_{\text {twist }}-5.25 \text {. }
$$

\section{Microstructural Characterization}

The microstructural characterization was performed using a scanning electron microscopy (SEM) with electron backscattering diffraction (EBSD) equipped (JSM-7800F FE-SEM, JEOL, Japan). The SEM specimen was cut from the cross section that is normal to the longitudinal direction of the bar sample, and then polished and chemically etched with $5 \mathrm{~g} \mathrm{CuCl}_{2}+100$ $\mathrm{ml} \mathrm{HCl}+100 \mathrm{ml} \mathrm{C}_{2} \mathrm{H}_{5} \mathrm{OH}$ solution to remove the $\gamma$ matrix and reveal the precipitates. The grain orientations were determined by an EBSD characterization, and then the SEM micrographs were obtained on grains with [111] and [100] orientations.

\section{RESULTS}

\section{A. $\gamma^{\prime \prime}$ Variant Distribution}

The characterized $\gamma^{\prime \prime}$ variant distribution in the [111] and [100] oriented grains for the sample after tensile-stress aging is shown in Figure 3. It can be seen that the $\gamma^{\prime \prime}$ precipitates are present in lenticular shape with 3 different orientations (3 different variants) in the [111] grain (Figure 3(a)). In the [100] oriented grain (Figure $3 b$ ), only the $\gamma^{\prime \prime}$ precipitates with disc-plane normal to the viewing direction (equivalent to the longitudinal direction of the sample) were observed; 
the other two variants with disc-plane parallel to the viewing direction were not found. $\gamma^{\prime \prime}$ variants lying on different faces of the cube are schematically shown in Figure 3. Round $\gamma^{\prime}$ particles with a smaller size than the $\gamma^{\prime \prime}$ are also observed in both grains. Our previous study, ${ }^{[17]}$ in which the IN718 sample underwent a 300 $\mathrm{MPa}$ tensile-stress aging at $790{ }^{\circ} \mathrm{C}$ for 5 hours, has estimated the $\gamma^{\prime} / \gamma^{\prime \prime}$ volume fraction ratio to be 0.36 . In the current study, the sizes of both $\gamma^{\prime}$ and $\gamma^{\prime \prime}$ precipitates are similar to those in the previous study; therefore, it is reasonable to consider the $\gamma^{\prime} / \gamma^{\prime \prime}$ volume fraction ratio to be 0.36 . This agrees with the $\gamma^{\prime} / \gamma^{\prime \prime}$ volume fraction ratio in an IN718 sample reported by Cozar and Pineau, ${ }^{[5]}$ which had a similar $\mathrm{Al}+\mathrm{Ti} / \mathrm{Nb}$ ratio to the present study. The three $\gamma^{\prime \prime}$ variants existed in approximately equal quantities in the [111] oriented grain, indicating that the $\gamma^{\prime \prime}$ variants did not experience preferential growth. This was due to the fact that the three variants in this grain oriented in a symmetric direction to the applied stress axis. In the [100] oriented grain, $\gamma^{\prime \prime}$ variant has been preferentially selected by the applied stress during aging, resulting in $\gamma^{\prime \prime}$ variant in the microstructure. The $\gamma^{\prime \prime}$ variant distributions in differently oriented grains after tensile-stress aging agree with our previous observation on the same material after aging heat treatment with a $300 \mathrm{MPa}$ tensile stress applied for 5 hours. ${ }^{[17]}$

\section{B. Diffraction Pattern}

Diffraction spectra obtained by bank 1 and bank 2 detectors for the stress-free aging at the beginning and end of aging are shown in Figure 4. Both bank 1 and bank 2 spectra show the peaks shifted to a lower d-spacing at the end of aging, indicating the lattice parameter of the $\gamma$ matrix phase decreased due to the aging. No $\gamma^{\prime \prime}$ peaks can be identified at the end of aging except for the partly overlapping $\{112\} \gamma^{\prime \prime}$ peak located to the right of $\{111\} \gamma$ peak (i.e., at a greater d-spacing). Such partly overlapping $\{112\} \gamma^{\prime \prime} /\{111\} \gamma$ peaks are observed in spectra from both detectors, meaning that the $\gamma^{\prime \prime}$ precipitates were formed during aging heat treatment.

Diffraction spectra obtained by bank 1 and bank 2 detectors for the tensile-stress aged sample at the beginning and end of aging are shown in Figure 5. The spectra at the beginning and end of aging are similar to those for stress-free aging: peaks shifted to a lower d-spacing and partly overlapping $\{112\} \gamma^{\prime \prime} /\{111\} \quad \gamma$ peaks. A noticeable difference is the apparent existence of the $\{004\} \gamma^{\prime \prime}$ peak, which is due to the SIVS on the $\gamma^{\prime \prime}$ variant distribution, in the spectrum from bank 1
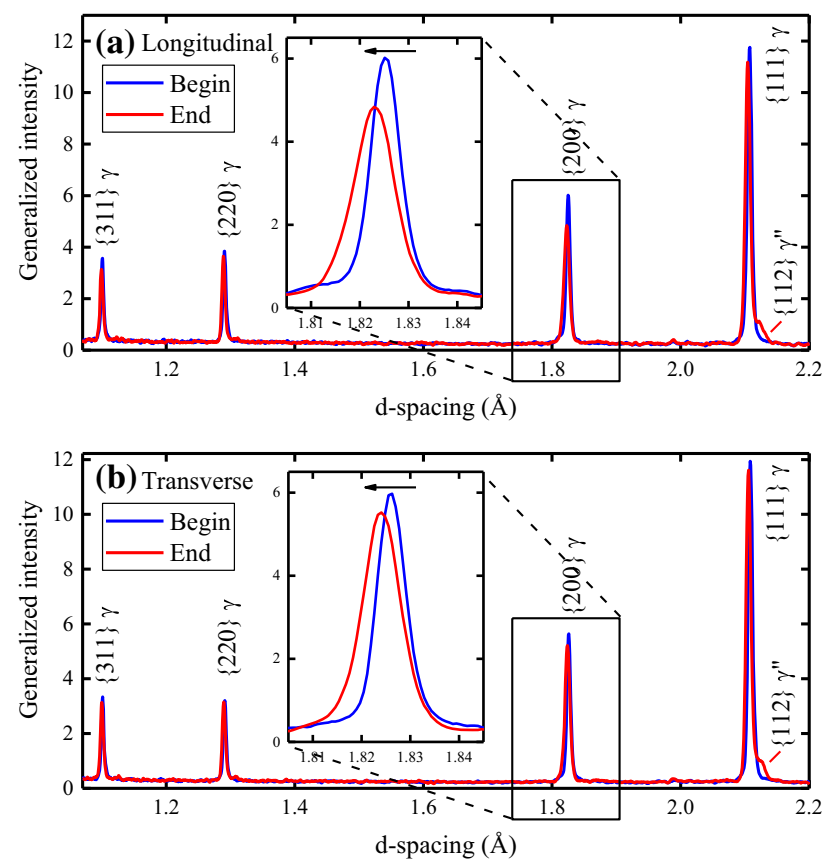

Fig. 4-Diffraction pattern for stress-free aging at the beginning and end of aging obtained along $(a)$ longitudinal direction and $(b)$ transverse direction. All four peaks shifted to a lower d-spacing after aging, an example is shown by the enlarged $\{200\}$ peak, indicating a decrease in lattice spacing of the $\gamma$ phase happened. Peak broadening is also observed as a decrease in the peak height after aging.
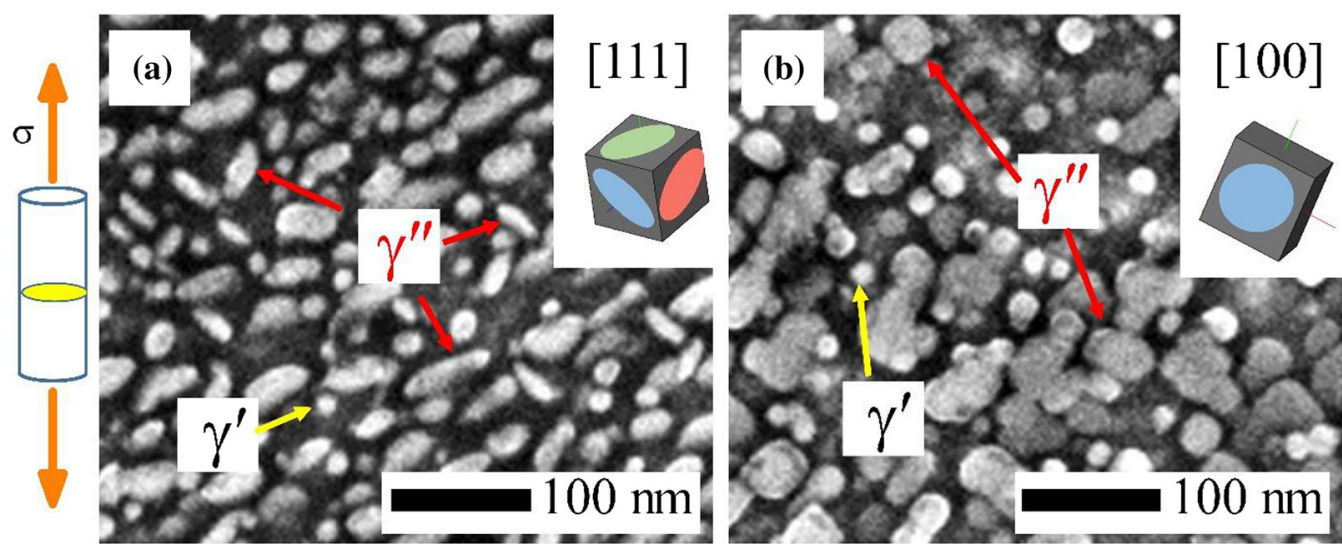

Fig. 3- $\gamma^{\prime \prime}$ variant distribution after tensile-stress aging in (a) [111] oriented grain, where three $\gamma^{\prime \prime}$ variants existed in approximately equal quantities, and (b) [100] oriented grain, where only one $\gamma^{\prime \prime}$ variant appeared. Round shape $\gamma^{\prime}$ particles are observed in these two grains. The micrographs were obtained from the view along longitudinal direction on the transverse cross section of the specimen bar. 
detector at the end of aging. Such SIVS effect resulted in a measurable intensity of the $\{004\} \gamma^{\prime \prime}$ peak that allowed accurate peak fitting. ${ }^{[17]}$ The $\{200\}$ peak obtained by bank 2 detector were contributed from the family of grains with $\{100\}$ plane normal to the transverse direction of the sample (also parallel to the diffraction vector for bank 2 detector). Due to the SIVS effect, the $\gamma^{\prime \prime}$ variant with disc-plane parallel to the longitudinal
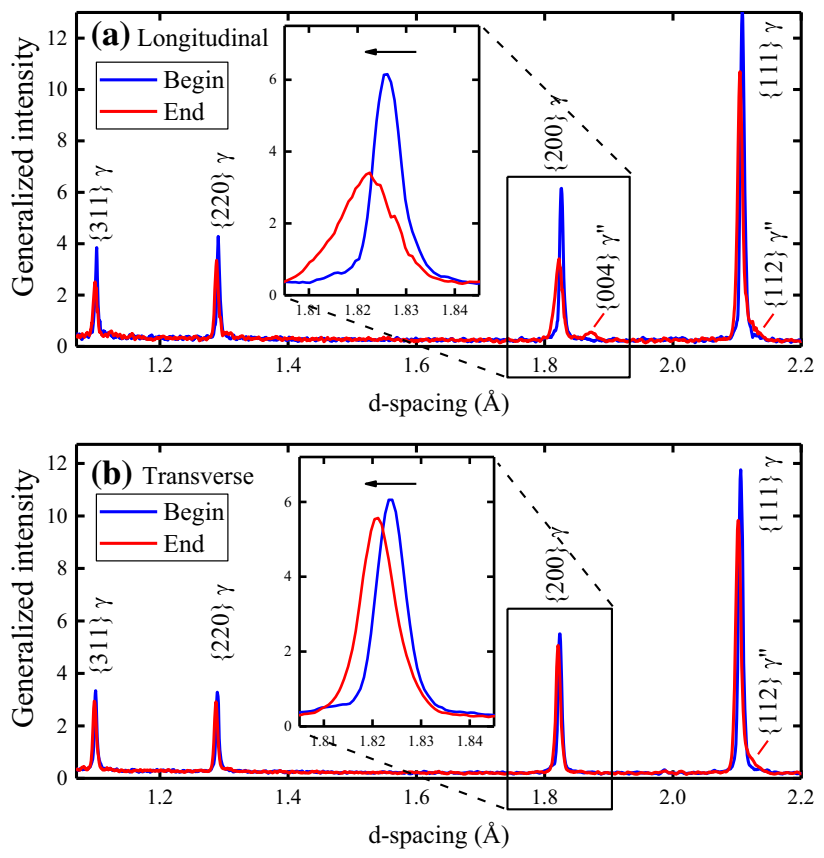

Fig. 5-Diffraction pattern for tensile-stress aging at the beginning and end of aging obtained along $(a)$ longitudinal direction and $(b)$ transverse direction. All four $\gamma$ peaks shifted to a lower d-spacing, an example is shown by the enlarged $\{200\}$ peak, indicating a decrease in lattice spacing of the $\gamma$ phase happened. A significant peak broadening of the $\{200\} \gamma$ peak in the longitudinal pattern is noticed. The $\{004\} \gamma^{\prime \prime}$ peak is clearly discerned at the end of aging in the longitudinal pattern. Such a significant peak broadening and the presence of $\{004\} \gamma^{\prime \prime}$ peak are not found in the pattern for stress-free aging (Fig. 4), implying these effects are attributed to the applied stress during aging. direction was absent in this family of grains, resulting in a larger intensity of the $\{200\} \gamma^{\prime \prime}$ peak in the spectrum for bank 2 detector. However, this $\{200\} \gamma^{\prime \prime}$ peak overlapped with the $\{200\} \gamma$ peak and would require a deconvolution to separate them.

\section{Lattice Parameter Evolution of the $\gamma$ Phase}

In order to obtain the average lattice parameter evolution of the $\gamma$ phase during aging, a Pawley-type refinement was performed to each of the diffraction spectrum, considering only the $\gamma$ phase since the $\gamma^{\prime \prime}$ phase has little influence in the fitting of the $\gamma$ peaks. The refinement was performed using OpenGenie software with the GSAS program. ${ }^{[31]}$ The average lattice parameter at a time point was obtained and the change in lattice parameter was calculated by

$$
\delta=\frac{a^{t}-a^{0}}{a^{0}}
$$

where $a^{t}$ and $a^{0}$ are lattice parameters at time (t) and at the beginning of aging, respectively. The change in lattice parameter along the longitudinal and transverse directions for both samples is shown in Figure 6. Decrease in lattice parameter was observed to develop during aging with a descending rate for each case, which was due to change in elemental composition of the $\gamma$ matrix (most likely the migration of $\mathrm{Nb}$ atoms from the $\gamma$ matrix to the $\gamma^{\prime \prime}$ precipitates). ${ }^{[32]}$ For the stress-free aging, lattice parameters for the longitudinal and transverse directions decreased in a very similar way, which was expected since little stresses were applied and the lattice parameter response should be isotropic. However, for the tensile-stress aging, the change in lattice parameter along the two directions started to split after about 1 hour of aging, reaching a difference of about $200 \times 10^{-6}$ at the end of aging. Such a difference could not be attributed to measurement uncertainty. Instead, it was more likely due to anisotropic microstructural evolution or elastic properties evolution associated with the applied stress.

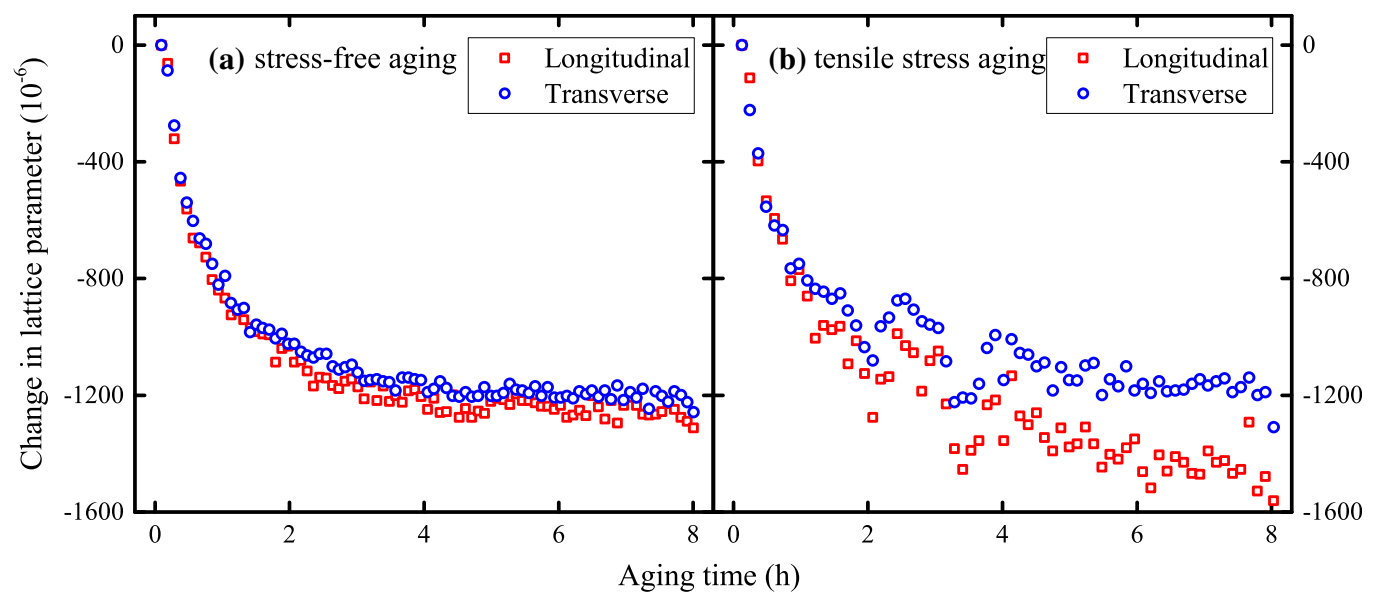

Fig. 6 - Change in lattice parameter of $\gamma$ phase for $(a)$ stress-free aging and $(b)$ tensile-stress aging. For clarity, error bars are not shown, the size of error bars is less than the size of the symbol. The fluctuations are understood to be due to the temperature fluctuations. 


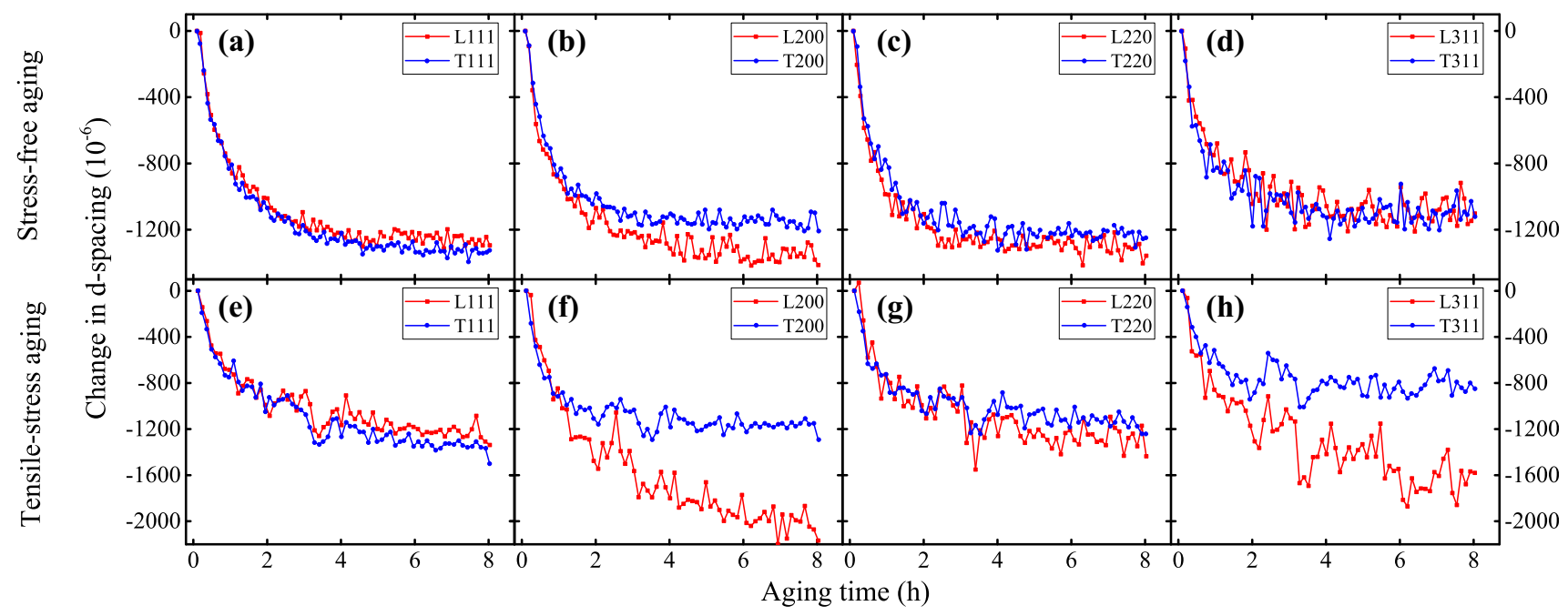

Fig. 7-Change in d-spacing of $\gamma$ phase for $(a)$ through $(d)$ stress-free aging and $(e)$ through $(h)$ tensile-stress aging. For the reason of clarity, error bars of uncertainty associated with peak fitting are not shown, the typical uncertainties for stress-free aging are between 20 and $80 \times 10^{-6}$, and for tensile-stress aging are between 30 and $140 \times 10^{-6}$.

In order to examine the reason accounted for the difference in lattice parameter evolution in Figure 6(b), change in $\mathrm{d}$-spacing of different $\{h k l\}$ planes for the $\gamma$ phase were calculated from single peak fitting of the first four $\{h k l\}$ peaks. The change in d-spacing for each case is plotted in Figure 7. For the stress-free aging, the d-spacing evolution has little difference both between different $\{h k l\}$ planes and between longitudinal and transverse directions. While for the tensile-stress aging, a different trend of $\mathrm{d}$-spacing evolution is found for the $\{200\}$ and $\{311\}$ planes. The d-spacing evolution split is found after 1 hour of aging, which is similar to the trend for the average lattice parameter evolution as shown in Figure 6(b). The difference in decrease of d-spacing between longitudinal and transverse directions reached about $800 \times 10^{-6}$ at the end of aging (Figures 7(f) and (h)). Meanwhile, the d-spacing evolution for $\{111\}$ and $\{220\}$ between longitudinal and transverse directions are similar (Figures 7(e) and (g)).

\section{D. $\gamma^{\prime \prime}$ Formation During Aging by Examining the Evolution of $\gamma$ Peak Width}

The evolution of full width at half max (FWHM) of the $\{111\}$ and $\{200\} \gamma$ peaks at each case during aging is shown in Figure 8. Peak width of each case for both stress-free aging and tensile-stress aging increased at the beginning of aging with a descending rate and reached a stable value after about 1.8 hours of aging. In addition, the $\{200\} \gamma$ peak in the longitudinal direction for the tensile-stress aging (Figure 8(c)) experienced a more significant broadening compared to the transverse direction and those for the stress-free aging.

As the instrumental peak broadening is likely to remain constant, any change in broadening of a diffraction peak would be due to the evolution of crystallite size and the microstrain gradient in the crystallite that arises from inhomogeneous microstructures including point defect, dislocations, and second phase precipitates.
In the current study, the evolution of peak broadening was unlikely attributed to the size of the diffracting crystallite since the grain size was a few tens of microns, which would contribute to little peak broadening. ${ }^{[33]}$ It was more likely that the $\gamma^{\prime \prime}$ precipitation accounted for the peak broadening. Elastic strain fields and misfit dislocations would be present around the $\gamma^{\prime \prime}$ particles as a result of lattice misfit between $\gamma^{\prime \prime}$ and $\gamma$ phases. During the early stage of $\gamma^{\prime \prime}$ precipitation, the volume fraction of the $\gamma^{\prime \prime}$ precipitates increased with aging time, increasing the magnitude of elastic strain fields and dislocation density. When the volume fraction of the $\gamma^{\prime \prime}$ precipitates reached a stable value, the peak width stopped increasing. Therefore, the evolution of peak width is correlated to the $\gamma^{\prime \prime}$ precipitation process, suggesting that the majority of $\gamma^{\prime \prime}$ precipitates were formed in the first 1.8 hours of aging. The peak width broadening for tensile-stress aging kept increasing gradually after the stage of rapid increase (1.8 hours). This could be due to the increased dislocation density that arose from creep at elevated temperature under $300 \mathrm{MPa}$ tensile stress.

\section{E. d-Spacing and Misfit Strain Evolution During Tensile-Stress Aging}

With the specific geometric setup in the experiment, attention was focused on the $\{200\}$ oriented grains since the principal axes of the crystal coincided with the diffraction vectors. Furthermore, $\gamma^{\prime \prime}$ variant selection due to the applied stress was evident in these grains and the lattice spacing of the $\gamma^{\prime \prime}$ along the a- and c-axes were derived from the diffraction peaks from these grains.

In the longitudinal spectrum for the tensile-stress aging as shown in Figure 5(a), \{004\} $\gamma^{\prime \prime}$ peak is clearly discerned, which allows the d-spacing of $\gamma^{\prime \prime}$ phase and the $\gamma$-to- $\gamma^{\prime \prime}$ peak intensity ratio to be obtained. The $\{200\} \gamma^{\prime \prime}$ peak which overlapped with the $\{200\} \gamma$ peak in the transverse spectrum was deconvoluted by fixing the $\gamma$-to- $\gamma^{\prime \prime}$ intensity ratio as obtained from the longitudinal 


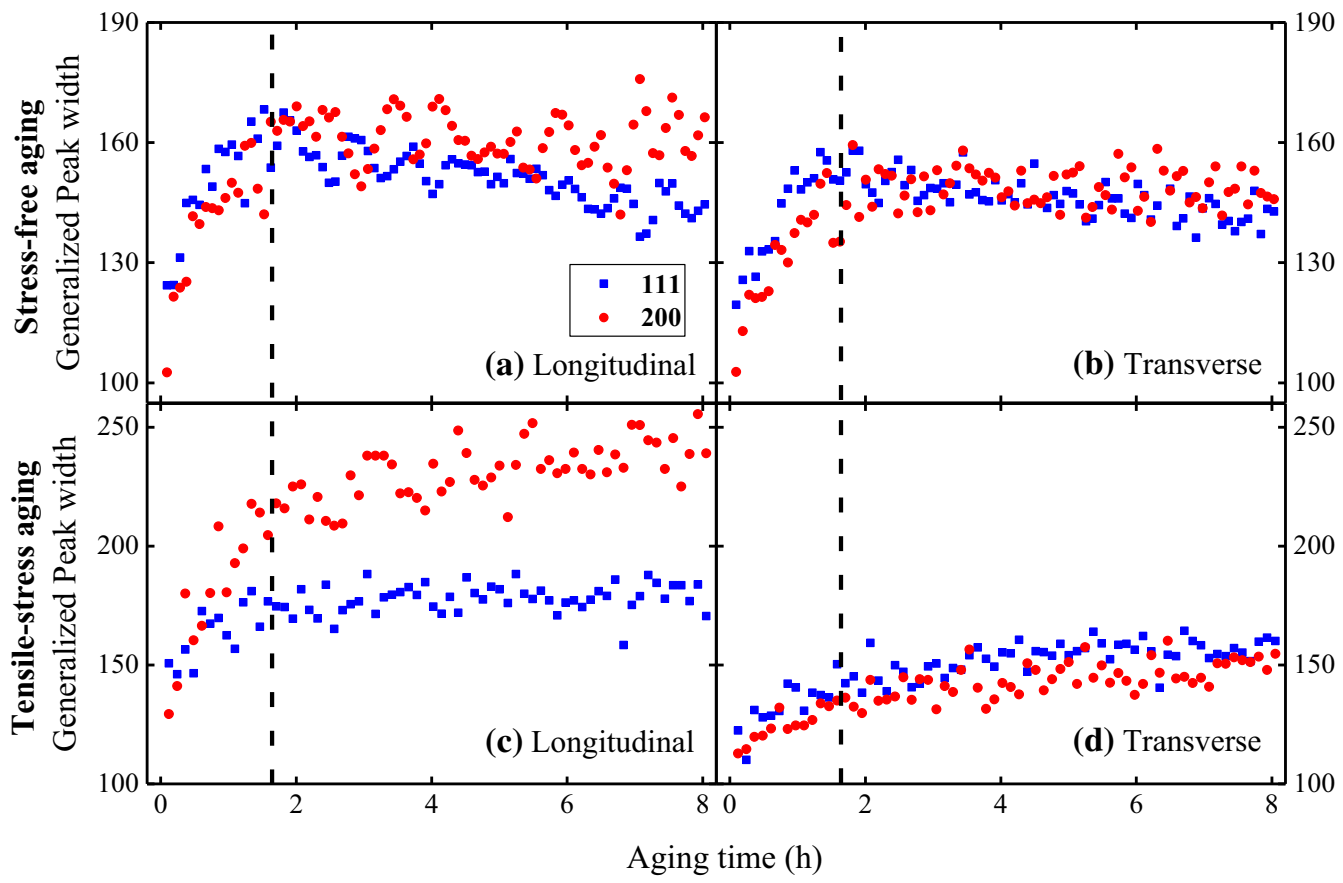

Fig. 8 - $\{111\}$ and $\{200\} \gamma$ peak width evolution along longitudinal and transverse directions during aging for $(a)$ and $(b)$ stress-free aging and $(c)$ and $(d)$ tensile-stress aging. For the reason of clarity, the error bars are not shown, the uncertainties of peak width associated with peak fitting are between 3 and 14 of the generalized peak width.

spectrum. The single peak fittings of the $\gamma^{\prime \prime}$ peak are shown in Figures 9(a) and (b). As the volume fraction of $\gamma^{\prime \prime}$ increased during precipitation, the $\{004\} \gamma^{\prime \prime}$ peak became visible after aging for 1 hour. Single peak fitting to the $\gamma^{\prime \prime}$ peak was performed from 1.8 hours of aging when most volume of the $\gamma^{\prime \prime}$ had been achieved, which allowed satisfactory fitting quality.

The evolution of longitudinal d-spacing of the $\{004\}$ $\gamma^{\prime \prime}$ and $\{200\} \gamma$ planes and transverse d-spacing of $\{200\}$ $\gamma^{\prime \prime}$ and $\{200\} \gamma$ planes are shown in Figure 10, with the corresponding misfit strains. Misfit strains in the $\gamma^{\prime \prime}$ precipitates were calculated using Eq. [3].

$$
\varepsilon=\frac{d_{\gamma \prime \prime}-d_{\gamma}}{d_{\gamma}}
$$

It is found that the d-spacing of the $\{004\} \gamma^{\prime \prime}$ peak in Figure 10(a) increased monotonically with aging time, while that of the $\{200\} \gamma^{\prime \prime}$ peak in Figure 10(b) increased and reached a maximum after aging for 5 hours before it decreased. The different d-spacing evolutions for $\{004\}$ and $\{200\} \gamma^{\prime \prime}$ peak cannot be explained by compositional change or decrease in coherency due to precipitate coarsening alone, indicating the two mechanisms occurred simultaneously during aging.

The misfit strains along $a$ - and $c$-axes shown in Figure 10(c) were calculated to be positive with the one along $c$-axis much larger than the one along $a$-axis, which are consistent with those misfit strains reported in the literature. Similar to the d-spacing, misfit strain along the $c$-axis in the $\gamma^{\prime \prime}$ precipitates increased monotonically, while a non-monotonic evolution for the $a$-axis.

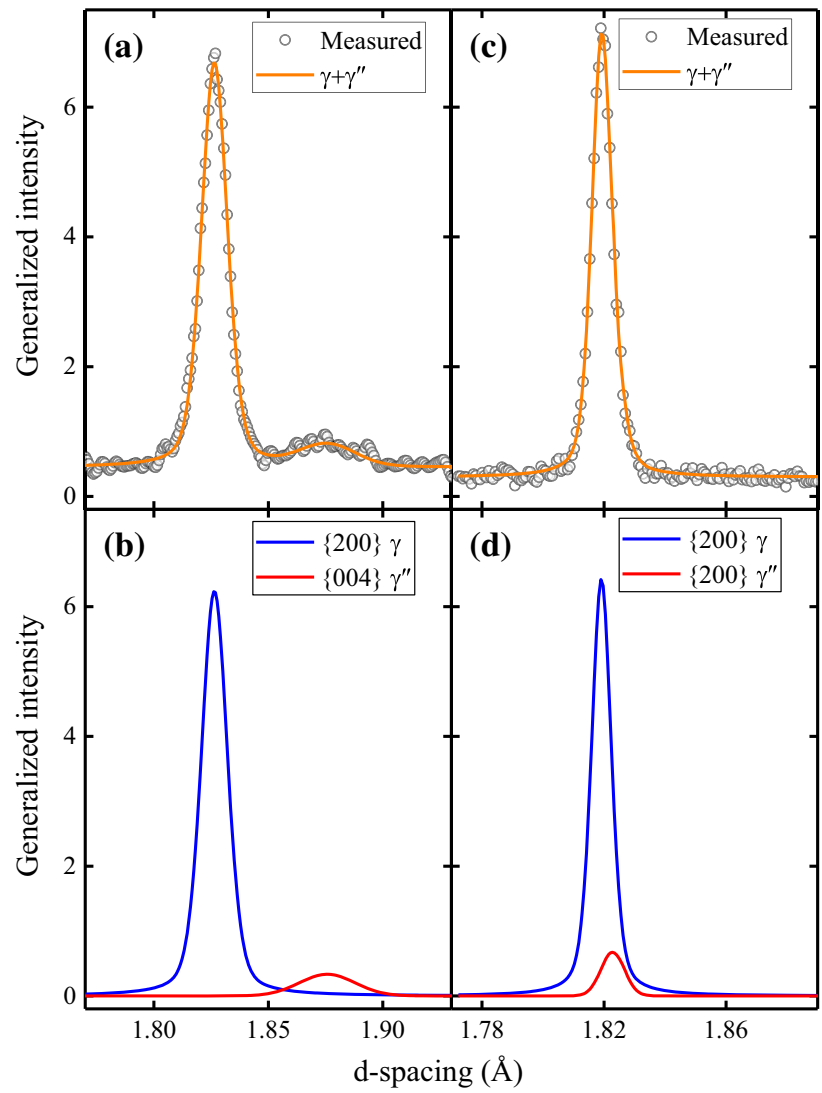

Fig. 9-(a) Fitted peaks and (b) deconvoluted $\{200\} \gamma+\{004\} \gamma^{\prime \prime}$ peaks in the longitudinal spectrum; (c) fitted peaks and $(d)$ deconvoluted $\{200\} \gamma+\{200\} \gamma^{\prime \prime}$ peaks in the transverse spectrum. 


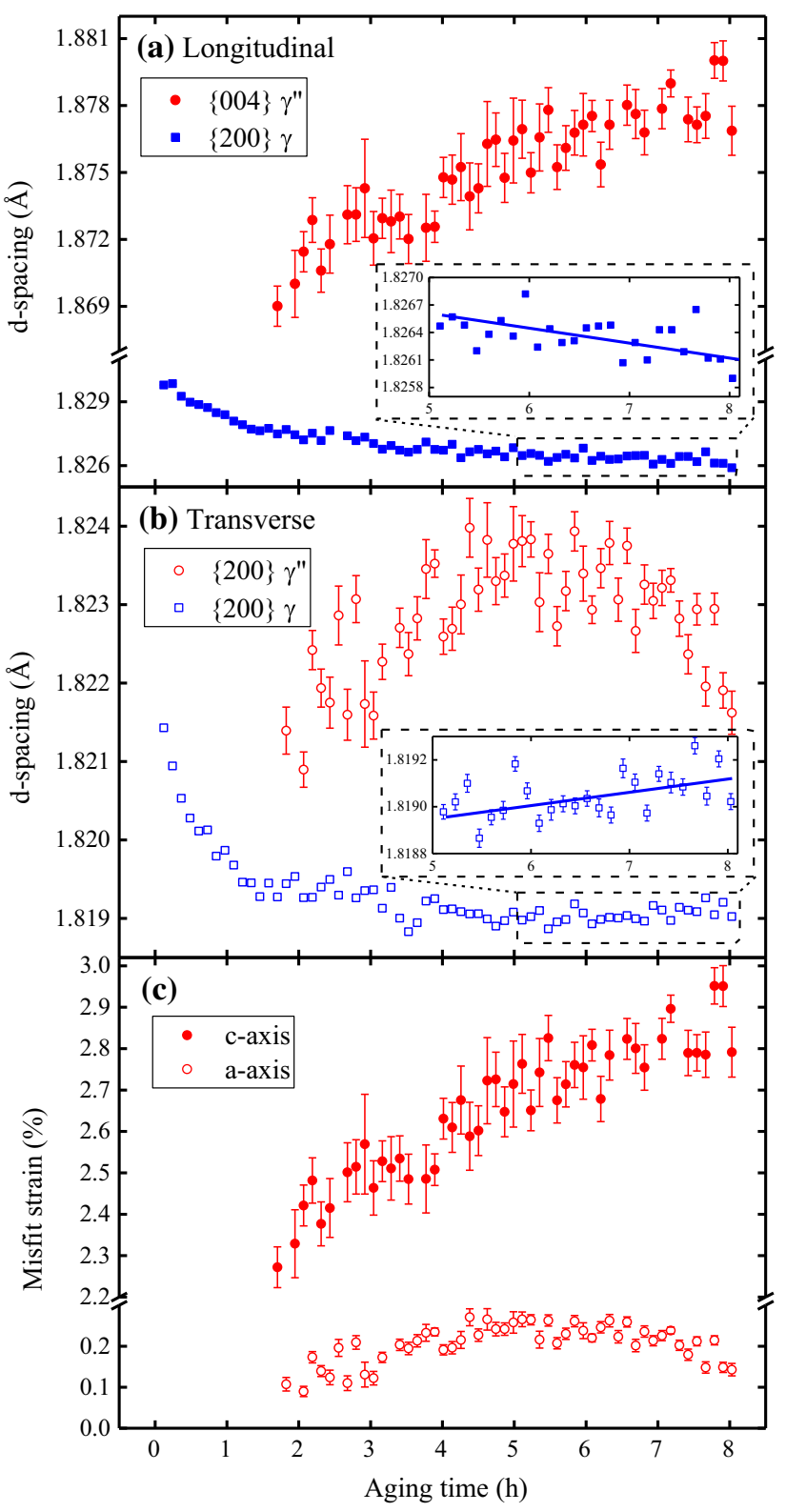

Fig. 10-d-Spacing evolution of $\gamma$ and $\gamma^{\prime \prime}$ phase for tensile-stress aging along $(a) c$-axis and (b) $a$-axis, and (c) corresponding misfit strain. Insets are the enlarged evolution of d-spacing for the $\gamma$ phase. Errors bars are shown for the uncertainties associated with fitting, except for those of $\{200\} \gamma$ that the error bars were less than the size of symbol.

\section{DISCUSSION}

\section{A. Stress-Induced Variant Selection Effect}

The $\gamma^{\prime \prime}$ variant selection effect during aging with stress applied has been discussed in our previous study ${ }^{[17]}$ and researches by others. ${ }^{[4,18]}$ These studies concluded that interactions between the applied stress and the misfit strain in different variants lead to different strain energy reductions. The variant that experiences the most reduction in strain energy will be selected to grow at the expense of the other variants. Since the compressive misfit strain in the $\gamma^{\prime \prime}$ is much larger along its $c$-axis (the disc-normal direction) than along the $a$-axis (disc-plane direction), the interaction energies between the compressive misfit strain and the applied tensile stress are different for different variants. The variant which has a smaller angle between its disc-normal direction and tensile loading direction experiences the more negative elastic strain interaction energy, and hence is favored to grow.

One may concern that the variant selection could be induced by creep strain. During creep, dislocation density is increased, and the dislocation provides a localized stress field that may cause the variant selection effect as similar as by the applied stress. In the current study, the total strain during aging heat treatment was monitored by a high-temperature ceramic extensometer. The creep strain was extracted from the recorded total strain by eliminating the strain from the lattice contraction. It was observed that a creep strain of 0.14 pct was developed at the end of the 8-hour aging. This creep strain seems too small to generate a large dislocation density and can lead to a prominent variant selection effect. On the other hand, as reported in the experiment by Oblak, ${ }^{[4]}$ a stress at the level of $69 \mathrm{MPa}$ has led to the variant selection effect as obvious as observed in the current study, suggesting the variant selection is attributed to the applied stress but not the creep strain.

\section{B. Lattice Spacing Evolution Due to Precipitation}

Isotropic $\gamma$ lattice evolutions for the stress-free aging are presented in Figures 6(a) and 7(a) through (d). The lattice parameter variations can be attributed to the compositional change during precipitation of the $\gamma^{\prime \prime}$ phase. When a tensile stress was applied during aging, anisotropic evolution of the $\gamma$ lattice parameter and $\mathrm{d}$-spacing are observed as shown in Figures 6(b) and $7(\mathrm{f})$, (h), respectively. In addition, the evolution of the $\gamma^{\prime \prime}$ d-spacing along the $a$ - and $c$-axes was obtained. The evolution of d-spacing can be possibly attributed to changes in (i) elasticity, (ii) localized element composition, (iii) $\gamma^{\prime \prime}$ precipitate morphology at different stages, and (iv) loss of coherency. Therefore, different stages during the aging heat treatment can be distinguished from the evolution of d-spacing of both the $\gamma$ and $\gamma^{\prime \prime}$ phases.

\section{Change in elastic modulus}

Changes in elastic modulus (increase or decrease in compliance) would lead to the evolution of d-spacing diverge between the longitudinal and transverse directions due to the Poisson's effect. This would happen to each family of grains. However, for the tensile-stress aging, divergence was only observed for $\{200\}$ and $\{311\}$ planes (Figures 7(f) and (h)) and not for $\{111\}$ and $\{220\}$ planes (Figures 7(e) and (g)). In addition, it would require a large change in modulus (about $40 \mathrm{pct}$ ) to tolerate the large difference $\left(800 \times 10^{-6}\right)$ in $\mathrm{d}$-spacing between the two directions. Therefore, it is unlikely that the diverged d-spacing between the two directions could be attributed to the change in elastic modulus. 


\section{Change in composition}

The $\gamma^{\prime \prime}$ phase is often represented stoichiometrically as $\mathrm{Ni}_{3} \mathrm{Nb}$. Lawitzki et al. ${ }^{[34]}$ has measured the elemental composition of the $\gamma^{\prime \prime}$ phase in IN718 samples with similar element composition to our samples using atom probe tomography, showing that the $\gamma^{\prime \prime}$ consists of 71.1 pet of $\mathrm{Ni}, 17.5$ pet of $\mathrm{Nb}, 1$ pet of $\mathrm{Al}, 4.3$ pet of $\mathrm{Ti}$, 2.4 pet of $\mathrm{Cr}, 1.8$ pet of $\mathrm{Fe}$, and 1.9 pet of Mo in at. pet. Simulation by thermodynamic software JMatPro shows that the $\gamma$ phase consists of 49 pct of $\mathrm{Ni}, 25$ pet of $\mathrm{Cr}$, 23 pct of Fe, 2 pet of Mo in at. pct and less of $\mathrm{Nb}, \mathrm{Al}$, and $\mathrm{Ti}$. $\mathrm{The} \mathrm{Nb}$ atom has a large atomic size and a large value for the Vegard's coefficient compared to other elements in IN718. ${ }^{[26]}$ During aging heat treatment, the $\mathrm{Nb}$ atoms migrate and cluster to form the $\gamma^{\prime \prime}$ phase and increase the lattice spacing of the $\gamma^{\prime \prime}$ phase by expanding the lattice. Meanwhile, the smaller size atoms are left in the $\gamma$ matrix phase resulting in a decrease in the lattice spacing of the $\gamma$ matrix phase (Figure 11(a)). The misfit strain by Eq. [3] will increase along both the $a$ - and $c$-axes of the $\gamma^{\prime \prime}$ phase due to the compositional change.

\section{Change in volume fraction}

The change in volume fraction may have influences on the evolution of lattice spacing. In order to reveal the effect, it is helpful to consider a simpler situation, assuming only volume fraction change takes place and no composition or size change. When precipitates are formed, misfit stresses are also generated in both phases. The level of misfit stresses in the precipitate depends only on its shape and stress-free misfit strain according to Eshelby's inclusion theory. ${ }^{[28]}$ The shape is determined by the size and the stress-free misfit strain is determined by the composition. Therefore, based on the assumption, the stresses in the precipitate do not rely on the volume fraction. The level of misfit stresses in the matrix can be calculated from the volume fractions: $\sigma_{\gamma}=-\frac{V_{\gamma}}{V_{\gamma}} \sigma_{\gamma}$. With the increasing volume fraction of the $\gamma^{\prime \prime}$ phase, the level of stresses in the $\gamma$ matrix (which is tensile) also increases. This leads to an increase in lattice parameter of the $\gamma$ phase. From Figures 10(a) and (b), it

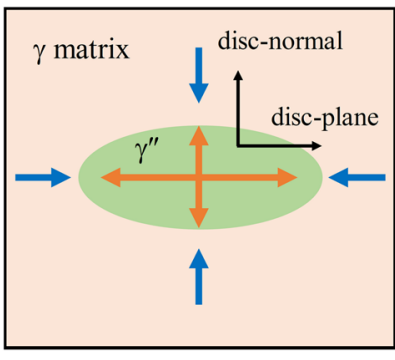

(a) Change in composition

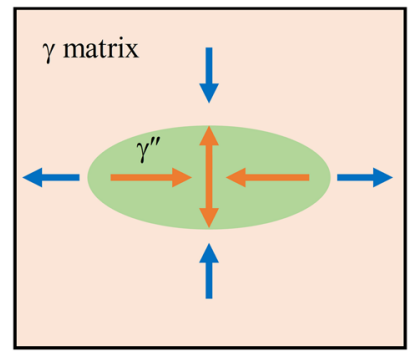

(b) Change in morphology
Fig. 11-Schematic illustration of lattice spacing evolution of the $\gamma^{\prime \prime}$ precipitate and the $\gamma$ matrix for $(a)$ compositional change and $(b)$ coarsening of the precipitate along a- and c-axes. The outward arrows indicate the expansion of the lattice, while the inward arrows for the contraction of the lattice. is observed that the lattice parameter of $\gamma$ decreased dramatically during the first few hours of aging, in which period is believed that most of the increase in volume fraction of the $\gamma^{\prime \prime}$ took place. This strongly suggests that the decrease in lattice parameter of $\gamma$ phase due to compositional change suppressed the increase in lattice parameter due to volume fraction change. Also in Figures 10(a) and (b), during the last few hours of aging, the lattice parameters of the $\gamma$ phase changed in opposite ways depending on the $\gamma$ variant orientation, which again cannot be attributed to the change in volume fraction.

\section{Change in morphology}

The morphology of a coherent precipitate is determined by the interfacial energy arising from the interface boundary and the elastic strain energy due to the lattice mismatch. ${ }^{[35]}$ For the precipitates with a BCT crystallographic structure, the crystal growth leads to a disc-like shape to minimize the sum of these two energies (i.e., interfacial energy and elastic strain energy). At the very early stage of precipitation when the particle size is small $(\sim<2 \mathrm{~nm})^{[17]}$ and the interfacial energy is dominant, the $\gamma^{\prime \prime}$ precipitates are in a spherical shape. As the size becomes larger and the elastic energy has a predominant effect, the $\gamma^{\prime \prime}$ precipitate will adopt a disc-like shape in order to accommodate the anisotropic misfit strain. As continued growth of the precipitate, the aspect ratio (thickness over diameter) tend to decrease accompanied with change in lattice spacing, leading to a gradual relaxation of misfit stress. In such a process, the positive constrained misfit strain along the normal of disc-plane will increase and the in-plane misfit strain will decrease. Therefore, as the precipitates continue to grow, the lattice spacings of the $\gamma^{\prime \prime}$ phase increase along the $c$-axis and decrease along the $a$-axis. Meanwhile, the lattice spacings of the $\gamma$ phase changes contrary to the $\gamma^{\prime \prime}$ phase along the two axes due to the requirement of stress balance (Figure 11(b)).

\section{Loss of coherency}

The $\gamma^{\prime \prime}$ precipitates can transform from fully coherent to semi-coherent due to loss of coherency during continued growth when the precipitates are larger than a critical size. Several studies have suggested the critical size for loss of coherency to be around 80 to $120 \mathrm{~nm} \cdot{ }^{[3,5,9]}$ In the current study, the mean major axis of the $\gamma^{\prime \prime}$ precipitates was around $50 \mathrm{~nm}$ which was less than the reported critical size. In addition, the mechanism for coherency loss has been proposed to be the formation of stacking faults within the precipitates which relaxes the $\gamma^{\prime \prime}$ lattice spacing along $a$-axis. ${ }^{[9,36]}$ Such a relaxation of the $\gamma^{\prime \prime}$ lattice spacing by plastic deformation should lead to a relaxation of the $\gamma$ lattice spacing along a-axis as well due to the balance of stresses. However, the evolution of lattice spacing along $a$-axis in Figure 10(b) shows a decrease for $\gamma^{\prime \prime}$ and an increase for $\gamma$, which cannot be attributed to coherency loss. Therefore, it is argued that loss of coherency did not happen during the aging heat treatment in the current study. 


\section{Lattice Spacing Evolution for Stress-Free Aging and Tensile-Stress Aging}

\section{Stress-free aging}

When no stress is applied during aging, the three $\gamma^{\prime \prime}$ variants tend to form in an approximately equal quantity. Although the change in the $\gamma^{\prime \prime}$ lattice spacing is anisotropic (Figure 11), the change in the $\gamma$ lattice spacing can be isotropic since the anisotropy is canceled out when the three $\gamma^{\prime \prime}$ variants are evenly distributed (Figure 12(a)). This explains the observed isotropic and monotonic decrease in the $\gamma$ lattice spacing during stress-free aging as shown in Figures 6(a) and 7(a) through (d).

\section{Tensile-stress aging}

When a tensile stress is applied during aging, the SIVS on the $\gamma^{\prime \prime}$ precipitates takes place. For the grains with $\langle 100\rangle$ parallel to the longitudinal direction, only the $\gamma^{\prime \prime}$ variant with the disc-plane normal to the applied stress axis remains, as schematically shown in Figure 12(b). The lattice spacing evolution correlated with the evolution of local element concentration and morphology can be distinguished into three stages. (i) At the early stage of aging when the compositional change effect is dominant, the applied stress would have little influence on the migration of the atoms, the compositional change in the $\gamma$ matrix is isotropic, and therefore the change in the $\gamma$ lattice spacing is isotropic. Thus, the first stage is

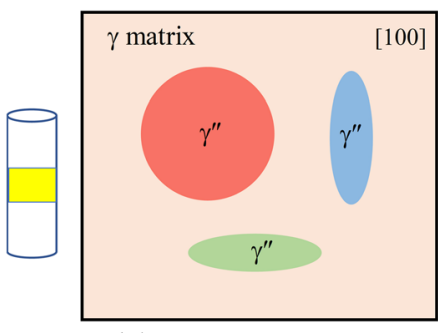

(a) Even variant distribution

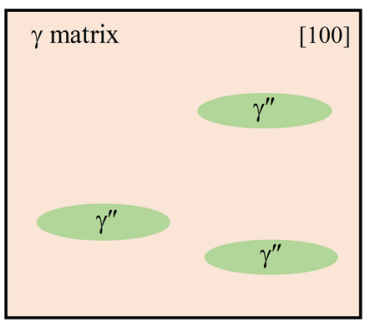

(b) Selected variant distribution
Fig. 12-Schematic illustrations of the $\gamma^{\prime \prime}$ variant in a [100] oriented grain with $(a)$ an even distribution from stress-free aging and $(b)$ a selected distribution from tensile-stress aging, viewing along the transverse direction. within the first hour of aging before the onset of separation as shown in Figure 7(f). (ii) When the effect by the compositional change weakens with the aging process and the effect by the morphological change takes place, these two competitive mechanisms impact on the evolution of lattice spacing and lead to the anisotropic decrease in the $\gamma$ lattice spacing and the increase in the $\gamma^{\prime \prime}$ lattice spacing. This can be referred to the second stage which is within the period of 1-5 hours of aging (indicated by the peak of the $\gamma^{\prime \prime}$ d-spacing in Figure 10(b)). (iii) When the effect by the compositional change becomes negligible, the lattice spacing evolution only depends on the coarsening effect, which can be referred to the third stage. At this stage, the lattice spacings of both phases evolve in the way as illustrated in Figure 11(b).

The evolution of lattice spacing of the $\gamma$ phase for the stress-free aging (the $\gamma^{\prime \prime}$ variants were evenly distributed) and evolution of lattice spacing of both the $\gamma$ and $\gamma^{\prime \prime}$ phases for the tensile-stress aging (the $\gamma^{\prime \prime}$ variants were selectively distributed) along longitudinal and transverse directions can be summarized in Table III.

3. In situ observation compared to ex situ observation

The existed time-temperature-transformation (TTT) diagrams for IN718 were established based on observations of precipitates using scanning electron microscopy. Due to the limit of SEM, fine precipitates at the early stage of aging are difficult to detect. The TTT curves only reflect the precipitates that have achieved a certain amount of volume fraction with size that large enough for detection. Therefore, the ex situ TTT diagram is not quantitatively accurate for the early stage of aging. On the other hand, the in situ diffraction technique provides an approach to monitor the precipitation/phase transformation process more quantitatively accurate, provided that the peaks from the parent phase and precipitated phase can be distinguished, compared to the approach by microstructure observation. In the current study, although the $\gamma^{\prime \prime}$ peaks cannot be discerned at the early stage of aging, the precipitation process can be evaluated by analyzing the evolution of d-spacing and breadth of the $\gamma$ peaks as shown in Figures 7 and 8. For the demands of an observation with a higher time resolution and better quantification,

Table III. Summary of Evolution of Lattice Spacing of the $\gamma$ Phase for the Stress-Free Aging (the $\gamma^{\prime \prime}$ Variants Were Evenly Distributed) and Evolution of Lattice Spacing of Both the $\gamma$ and $\gamma^{\prime \prime}$ Phases for the Tensile-Stress Aging (the $\gamma^{\prime \prime}$ Variants Were Selectively Distributed) Along Longitudinal and Transverse Directions

\begin{tabular}{|c|c|c|c|c|c|}
\hline \multirow[b]{2}{*}{ Stage } & \multirow[b]{2}{*}{ Evolution } & \multirow[b]{2}{*}{ Direction } & \multirow{2}{*}{$\begin{array}{c}\text { Even Variant Distribution } \\
\qquad \gamma\end{array}$} & \multicolumn{2}{|c|}{ Selected Variant Distribution } \\
\hline & & & & $\gamma$ & $\gamma^{\prime \prime}$ \\
\hline I & composition & $\begin{array}{l}\text { longitudinal } \\
\text { transverse }\end{array}$ & $\begin{array}{l}\downarrow \\
\downarrow\end{array}$ & $\begin{array}{l}\downarrow \\
\downarrow\end{array}$ & $\begin{array}{l}\text { not observed } \\
\text { not observed }\end{array}$ \\
\hline II & composition + morphology & $\begin{array}{l}\text { longitudinal } \\
\text { transverse }\end{array}$ & $\begin{array}{l}\downarrow \\
\downarrow\end{array}$ & $\begin{array}{l}\downarrow \\
\downarrow\end{array}$ & $\begin{array}{l}\uparrow \\
\uparrow\end{array}$ \\
\hline III & morphology & $\begin{array}{l}\text { longitudinal } \\
\text { transverse }\end{array}$ & $\begin{array}{l}\text { little change } \\
\text { little change }\end{array}$ & $\begin{array}{l}\downarrow \\
\uparrow\end{array}$ & $\begin{array}{l}\uparrow \\
\downarrow\end{array}$ \\
\hline
\end{tabular}

Evolution of lattice spacing for the $\gamma^{\prime \prime}$ phase for the stress-free aging was not obtained. The arrow $\downarrow$ represents a decrease in lattice spacing and $\uparrow$ represents an increase in lattice spacing. 
synchrotron X-ray would be a better choice than neutron techniques. ${ }^{[37]}$ One would expect a more accurate TTT diagram at the early stage of aging can be established by monitoring the precipitation process of the material for various temperatures using diffraction techniques. The current study shows a feasible approach to monitor the aging process and evolution of d-spacing/ misfit strain of IN718 using neutron diffraction, which will benefit the understanding on the mechanisms of precipitation process.

\section{CONCLUSIONS}

From the results of this in situ neutron diffraction during aging heat treatment of IN718, the following conclusions can be drawn:

(1) Majority of the $\gamma^{\prime \prime}$ precipitation is achieved in the first 1.8 hours of aging as suggested by the evolution of peak width.

(2) The lattice spacing of different $h k l$ planes of the $\gamma$ phase decreases in an isotropic manner for the stress-free aging primarily due to the uniform distribution of the three $\gamma^{\prime \prime}$ variants.

(3) The aging with tensile stress leads to anisotropic evolution of the $\gamma$ lattice spacing due to the SIVS effect.

(4) The diffraction data demonstrate three stages of lattice spacing evolution due to compositional and morphological changes during aging:

(i) Stage I, within which the compositional change is dominant during the first hour of aging, the $\gamma$ lattice spacing decreases isotropically.

(ii) Stage II, in the period of 1 to 5 hours of aging, the effect by compositional change weakens with aging time and the effect by morphological change becomes comparable. Anisotropic decrease in the $\gamma$ lattice spacing and increase in the $\gamma^{\prime \prime}$ lattice spacing are observed.

(iii) Stage III, after 5 hours of aging, the effect by compositional change is negligible and the effect by morphological change is dominant. The $\gamma$ lattice spacing decreases in the $c$-axis direction and increases in the $a$-axis direction of the $\gamma^{\prime \prime}$ phase. In addition, the $\gamma^{\prime \prime}$ lattice spacing evolves in an opposite way compared to the $\gamma$ phase.

\section{ACKNOWLEDGMENTS}

Ruiyao Zhang gratefully acknowledges the financial support from the Centre for Doctoral Training in Innovative Metal Processing (IMPaCT) funded by the UK Engineering and Physical Sciences Research Council (EPSRC), Grant Reference EP/L016206/1. We also acknowledge the allocation of beam time (RB1655022) at ENGIN-X, ISIS, Rutherford Appleton Laboratory.

\section{OPEN ACCESS}

This article is distributed under the terms of the Creative Commons Attribution 4.0 International License (http://creativecommons.org/licenses/by/4.0/), which permits unrestricted use, distribution, and reproduction in any medium, provided you give appropriate credit to the original author(s) and the source, provide a link to the Creative Commons license, and indicate if changes were made.

\section{REFERENCES}

1. M.C. Chaturvedi and Y.F. Han: Met. Sci., 1983, vol. 17, pp. 145-49

2. J.M. Oblak, D.S. Duvall, and D.F. Paulonis: Mater. Sci. Eng., 1974, vol. 13, pp. 51-56.

3. C. Slama, C. Servant, and G. Cizeron: J. Mater. Res., 1997, vol. 12, pp. 2298-2316.

4. J.M. Oblak, D.F. Paulonis, and D.S. Duvall: Metall. Trans., 1974, vol. 5, p. 143.

5. R. Cozar and A. Pineau: Metall. Mater. Trans. B, 1973, vol. 4B, pp. 47-59.

6. H. Qin, Z. Bi, H. Yu, G. Feng, J. Du, and J. Zhang: J. Alloys Compd., 2018, vol. 740, pp. 997-1006.

7. H. Qin, Z. Bi, H. Yu, G. Feng, R. Zhang, X. Guo, H. Chi, J. Du, and J. Zhang: Mater. Sci. Eng. A, 2018, vol. 728, pp. 183-95.

8. D. McAllister, D. Lv, B. Peterson, H. Deutchman, Y. Wang, and M.J. Mills: Scr. Mater., 2016, vol. 115, pp. 108-12.

9. Y. Ji, Y. Lou, M. Qu, J.D. Rowatt, F. Zhang, T.W. Simpson, and L.-Q. Chen: Metall. Mater. Trans. A, 2016, vol. 47, pp. 3235-47.

10. D.P. McAllister, Ph.D Thesis, The Ohio State University, 2016.

11. N. Zhou, D.C. Lv, H.L. Zhang, D. McAllister, F. Zhang, M.J. Mills, and Y. Wang: Acta Mater., 2014, vol. 65, pp. 270-86.

12. A. Devaux, L. Nazé, R. Molins, A. Pineau, A. Organista, J.Y. Guédou, J.F. Uginet, and P. Héritier: Mater. Sci. Eng. A, 2008, vol. 486, pp. 117-22.

13. M. Sundararaman, P. Mukhopadhyay, and S. Banerjee: Metall. Trans. A, 1992, vol. 23, pp. 2015-28.

14. M. Sundararaman, P. Mukhopadhyay, and S. Banerjee: Acta Metall., 1988, vol. 36, pp. 847-64.

15. H. Qin, Z. Bi, D. Li, R. Zhang, T.L. Lee, G. Feng, H. Dong, J. Du, and J. Zhang: Mater. Sci. Eng. A, 2019, vol. 742, pp. 493-500.

16. M.J. Donachie and S.J. Donachie: Superalloys: A Technical Guide, 2nd ed., ASM International, Materials Park, 2002.

17. R.Y. Zhang, H.L. Qin, Z.N. Bi, J. Li, S. Paul, T.L. Lee, B. Nenchev, J. Zhang, S. Kabra, J. Kelleher, and H.B. Dong: Metall. Mater. Trans. A, 2019, vol. 50A, pp. 5421-32.

18. M. Gao, D.G. Harlow, R.P. Wei, and S. Chen: Metall. Mater. Trans. A, 1996, vol. 27A, pp. 3391-98.

19. D. Jianxin, X. Xishan, and Z. Shouhua: Scripta Metall. Mater., 1995, vol. 33, pp. 1933-40.

20. Y.F. Han, P. Deb, and M.C. Chaturvedi: Met. Sci., 1982, vol. 16, pp. $555-62$.

21. D.F. Paulonis, J.M. Oblak, and D.S. Duvall: ASM Trans. Quart., 1969, vol. 62, pp. 611-22.

22. I. Kirman and D.H. Warrington: Metall. Trans., 1970, vol. 1, pp. 2667-75.

23. M.G. Burke and M.K. Miller: in Superalloys 718, 625 and Various Derivatives, The Minerals, E.A. Loria, ed., Metals \& Materials Society, Pittsburgh, 1991.

24. M. Sundararaman and P. Mukhopadhyay: Mater. Charact., 1993, vol. 31, pp. 191-96.

25. C. Slama and M. Abdellaoui: J. Alloys Compd., 2000, vol. 306, pp. $277-84$. 
26. R.C. Reed: The Superalloys: Fundamentals and Applications, 1st ed., Cambridge University Press, Cambridge, 2006.

27. S.H. Wen, E. Kostlan, M. Hong, A.G. Khachaturyan, and J.W. Morris: Acta Metall., 1981, vol. 29, pp. 1247-54.

28. J.D. Eshelby: Proc. R. Soc. Lond. Ser. A, 1957, vol. 241, pp. 376-96.

29. T. Mura: Micromechanics of Defects in Solids, Springer, Dordrecht, 1987.

30. J. Santisteban, M. Daymond, J. James, and L. Edwards: J. Appl. Crystallogr., 2006, vol. 39, pp. 812-25.

31. A.C. Larson, R.B. Von Dreele, Los Alamos National Laboratory Report LAUR, 2004, pp. 84-748.

32. P.E. Aba-Perea, T. Pirling, and M. Preuss: Mater. Des., 2016, vol. 110 , pp. $925-31$.
33. M.T. Hutchings, P.J. Withers, T.M. Holden, and T. Lorentzen: Introduction to the Characterization of Residual Stress by Neutron Diffraction, Taylor \& Francis, Boca Raton, Fla, 2005.

34. R. Lawitzki, S. Hassan, L. Karge, J. Wagner, D. Wang, J. von Kobylinski, C. Krempaszky, M. Hofmann, R. Gilles, and G. Schmitz: Acta Mater., 2019, vol. 163, pp. 28-39.

35. D.Y. Li and L.Q. Chen: Acta Mater., 1998, vol. 46, pp. 2573-85.

36. M. Sundararaman, P. Mukhopadhyay, and S. Banerjee: Metall. Trans. A, 1988, vol. 19, pp. 453-65.

37. D.M. Collins, D.J. Crudden, E. Alabort, T. Connolley, and R.C. Reed: Acta Mater., 2015, vol. 94, pp. 244-56.

Publisher's Note Springer Nature remains neutral with regard to jurisdictional claims in published maps and institutional affiliations. 